\title{
Skafoid harici karpal kemik kırıkları
}

\author{
Carpal fractures excluding the scaphoid
}

\author{
Eren Cansü
}

Marmara Üniversitesi Tıp Fakültesi, Ortopedi ve Travmatoloji Anabilim Dalı

\begin{abstract}
Karpal kemik kırıkları tüm iskelet sistemi kırıklarının az bir oranını oluşturmaktadır. Her ne kadar hiperfleksiyonun da önemli olduğu söylense de, esas üzerinde durulan oluş mekanizması hiperekstansiyondur. Ancak karpal yaralanmaların çeşitliliği düşünüldüğünde sadece tek bir mekanizmanın sorumlu olmadığı açıktır. Karpal kemik kırıklarının en yaygın olanı skafoid kırıklarıdır; ancak, el bileği travmalarında skafoid kırığı olmadan da diğer karpal kemiklerde kırık olabileceği veya skafoid kırığına başka bir karpal kemik kırığının eşlik edebileceği akılda bulundurulmalıdır. Karpal kemik kırıklarının tanısı zordur ve sıklıkla atlanır. Tanı için belki de en önemli yöntem, şüphelenmektir; bundan sonra istenecek ileri radyolojik yöntemler ile kırıklar rahatlıkla teşhis edilebilir. Karpal kemiklerin kırıkları ve kırıklı çıkılarının tedavisinde hedef, ağrısız el bilek fonksiyonu sağlamaktır. Genel olarak stabil ve ayrışmamış kırıklar, alçılama ile konservatif olarak tedavi edilebilir. Ayrışmış, büyük parçalı kırıklara osteosentez uygulanabilirken, küçük ve/veya çok sayıda parçalar var ise, bunlar cerrahi olarak çıkarılabilir. Ancak tanı atlanır ve tedavi gecikirse, el bileğindeki ağı, kalıcı hasar ve artroz riski de artar.
\end{abstract}

Anahtar sözcükler: karpal eklemler; kırıklar; çıkıklar; el bileği; travma
Carpal fractures are rare injuries. Although it is suggested that hyperflexion is important, hyperextension is considered to be the major mechanism creating these injuries. However, if we keep in mind the variety of the carpal fractures, it is obvious that more than a single mechanism is responsible for the entire spectrum of carpal fractures and fracture-dislocations. Although scaphoid fractures are the most common, other isolated fractures or accompanying carpal fractures to scaphoid fractures should be kept in mind when dealing with wrist trauma. Carpal fractures are hard to diagnose and they are usually missed. The best way to diagnose is to suspect: if suspected, it can be easily diagnosed with advanced radiological methods. The primary goal in the treatment of carpal fractures and fracture-dislocations is the preservation of a painless wrist function. As a general rule, stable and nondisplaced fractures are treated conservatively with casting. Osteosynthesis can be the treatment of displaced and large fragment fractures. If there are single or multiple small fragments, these can be excised surgically. Risks of wrist pain, residual damage and arthrosis will increase if these lesions are misdiagnosed or the treatment is delayed.

Key words: carpal joints; fractures; dislocations; wrist; trauma

Genel üst ekstremite yaralanmalarında olduğu gibi karpal kemik kırıklarına da en sık neden olan mekanizma açık el üstüne düşmedir. Düşme sonucu oluşan enerji, hiperekstansiyon sonucu gelişen güçlere distal radiusun direnç göstermesi ile distal karpal sırada yoğunlaşabilir. Yaralanma mekanizması devam ederse, bu enerji volar karpal bağlar üzerinden iletilerek proksimal karpal sıra çevresinde ekstansiyon momenti oluşturur. Bu bağların kopması veya lunat çevresinde gelişen makaslayıc kuvvetler ile perilunat tip veya "küçük yay" yaralanması meydana gelir. Karpal kırıklar veya bağ yaralanmaları lunat çevresindeki yayda oluşabilir. El bileğinin volar tarafında gerilme kuvvetlerine bağlı

- Illetişim adresi: Op. Dr. Eren Cansü, Mehtap sok. 34/7, Caddebostan, İstanbul Tel: 0216 - 3859056 e-posta: erencansu@hotmail.com

- Geliș tarihi: 25 Șubat 2014 Kabul tarihi: 25 Subat 2014 
karpal kırık oluşurken, dorsalde kompresyon sonucu kortikal parçalanmalar görülebilir. Skafoid, kapitat ve trikuetrumun birlikte veya ayrı ayrı eşlik ettiği perilunat instabiliteler ise "büyük yay" yaralanmaları olarak adlandırılır. ${ }^{[1]}$

Aksiyel tip yaralanmalar, ön-arka planda etki eden aşırı kompresif kuvvetin karpal kemikler ve metakarpları birbirlerinden ulnar ve radyal yönlere ayırması ile meydana gelir. Sıklıkla pres yaralanması, patlama gibi ağır iş kazaları sonucunda oluştuklarından, genellikle açık kırık ve çıkıklara ciddi yumuşak doku hasarları ve kayıpları eşlik eder. Bu durum oldukça nadir gözükse de hastada önemli bir morbiditeye neden olur. GarciaElias ve arkadaşları, 16 yıl boyunca karpal kırık veya kırıklı çıkık nedeni ile tedavi edilen 1140 hastanın sadece 16'sında aksiyel tip yaralanma olduğunu bildirmişler, prognozun ise karpal uyumsuzluktan ziyade yumuşak dokudaki hasar ile ilişkili olduğunu belirtmişlerdir. ${ }^{[2]}$

Kopma kırıklarına genellikle trikuetrumun volar veya dorsal yüzünde rastlanılsa da, trapezium, hamatum çengeli ve pisiform da etkilenebilir.

Garcia-Elias, karpal kemiklerin ortak bazı özelliklerini şöyle belirtmiştir: Bu yaralanmalar genellikle yüksek fonksiyonel beklentisi olan genç bireylerde olur. ilk başvuru anında sıklıkla atlanır. Kırılan kemiğin küçük boyutu cerrahi redüksiyonu zorlaştırır ve beslenmesini bozar.

Ayrışmış kırık, eklem uyumunu ciddi şekilde bozarak dejeneratif değişikliklere yol açabilir. İnstabil karpal kırıklara sıklıkla bağ yaralanmaları eşlik eder. Karpal kemikler ile damar-sinir ve tendonların yakın komşuluğundan dolayı, ayrışmış kemik parçaları ikincil sinir tuzaklanmalarına ve tendon kopmalarına neden olabilir. ${ }^{[1]}$

Benzer mekanizma ile meydana gelen distal radius kırıklarında da karpal kemiklerde ek kırıklar olabilmektedir. Önceden de belirtildiği gibi sıklıkla gözden kaçan bu kırıklar, rahatlıkla tanı konan daha büyük bir kırık varlığında belki de daha sık atlanmaktadır. Yüz yetmiş distal radius kırığını inceleyen bir araştırmada, 11 hastada toplam 15 karpal kemik kırığı saptanmış ve bu sayının hiç de azımsanmaması gerektiği bildirilmiştir. ${ }^{[3]}$

Skafoidi hariç tuttuğumuz karpal kemik kırıklarında en sık kırılan kemiğin trikuetrum olduğu birçok yazar tarafindan kabul edilmektedir. ${ }^{[1,3-6]}$ Bazı serilerde lunatın daha sık kırıldığı bildirilse de, bu olgulara Kienböck hastaları da dahil edilmiştir. ${ }^{[1]}$

\section{TRIKUETRUM KIRIKLARI}

Skafoidden sonra en sık olarak görülen trikuetrum kırıkları genellikle üç tipte incelenir: Dorsal korteks kırıkları, açık ara en sık görülen tiptir. Bu yaralanma tipi için farklı mekanizmalar ortaya atılmıştır. Aşırı palmar fleksiyon ve radyal deviyasyon, dorsal radyotrikuetral ve trikuetroskafoid bağların çekmesi ile kopma kırıklarına, el bileğinin ekstansiyonunda hamatum proksimal köşesinin uyguladığı makaslama kuvveti ise trikuetrumun distal dorsalinde kırı̆ga neden olabilir (Şekil 1). Diğer bir mekanizmayı ise Levy tanımlamıştır. ${ }^{[7]}$ En sık
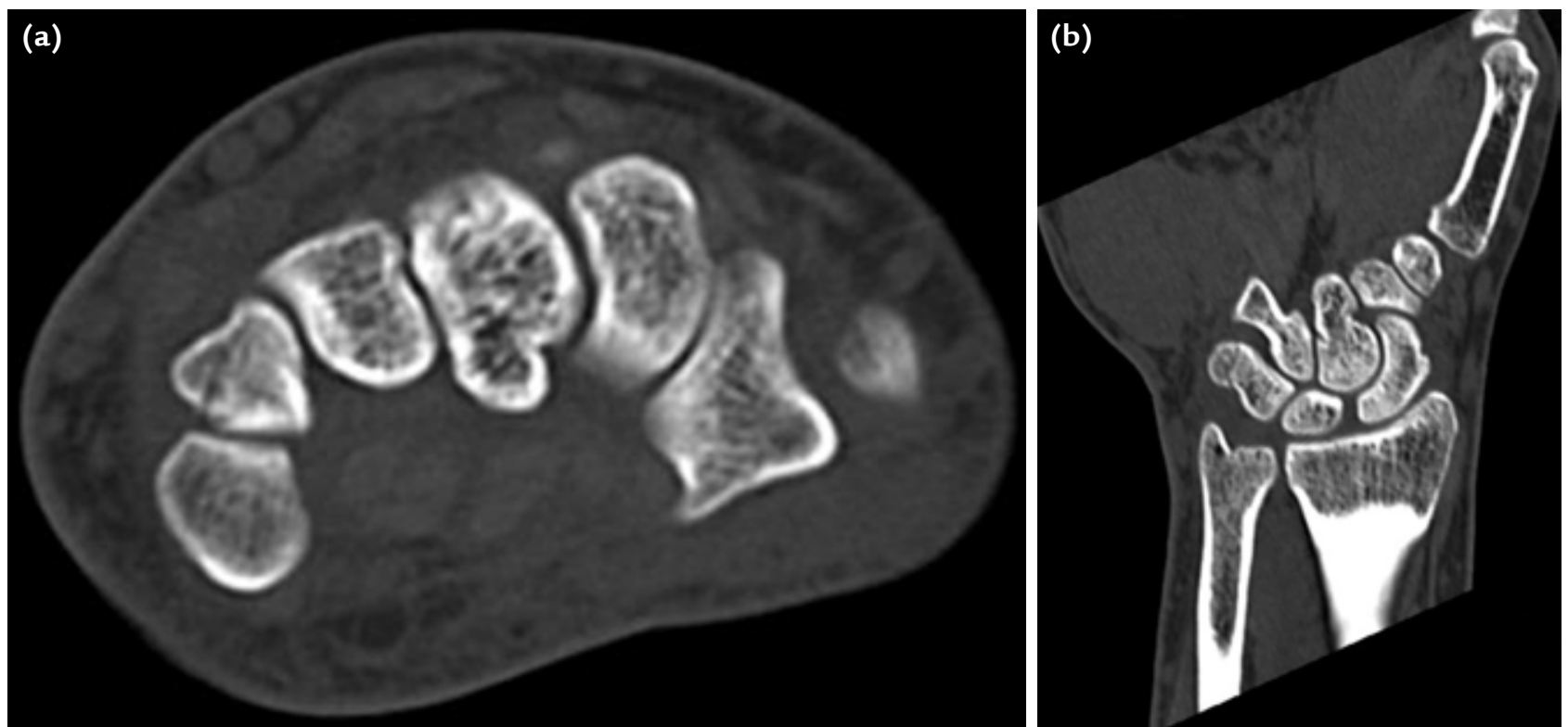

Şekil 1. a, b. Radyografide görülmeyen ancak BT ile saptanan trikuetrum kırığının aksiyel (a) ve koronal (b) kesitleri. 
görülen yaralanma şekli olan el üzerine düşme sonucu el bileğinin dorsifleksiyon ve ulnar deviyasyona gelmesi ve ulna stiloidinin trikuetruma keski gibi dayanması ile yontulma tarzında kırık oluşur. Daha sonra yapılan bir çalışma da, trikuetrum kırığı olan hastaların ulna stiloid boylarının, yaralanması olmayan bireylere göre anlamlı olarak uzun olduğunu göstererek bu mekanizmayı desteklemiştir. ${ }^{[8]}$

Cisim kırıklarına ikinci sıklıkta rastlansa da, bunlar oldukça nadirdir. Yüksek enerjili bir yaralanma gerektirdiğinden, daha çok perilunat çıkıklarla birlikte görülürler (Şekil 2). Direkt grafide görülmeleri küçük parça ve kopma kırıklarına göre daha kolay olsa da, şüphede kalınan durumlarda bilgisayarlı tomografi (BT) veya manyetik rezonans (MR) ile aranmalıdır. Böylece, erken tanı ile ağrı nedeni olabilecek kaynamama durumu engellenebilir.

Trikuetrumun volar kopma kırıkları da bildirilmiştir. Bunlar volar trikuetral bağların hasarları ile birlikte olduklarından, gözükenden daha ciddi yaralanmalar olup karpal instabilite oluşturabilir. Smith ve Murray, volar kopma kırığı nedeniyle tedavi edilen beş hastanın tümünde ağrının devam ettiğini ve çeşitli seviyelerde instabilite saptandığını bildirmişlerdir. ${ }^{[9]}$

\section{Tedavi}

Trikuetrum kırıklarının neredeyse tamamı dorsal kırığı şeklinde olduğundan 4-6 hafta immobilizasyonu içeren konservatif yöntemler ile tedavi edilirler. El bilek travmalarında, düşünülenden daha fazla kemik ve yumuşak doku yaralanması olabilmektedir. ${ }^{[5]}$ Kırıklarla birlikte de görülen bu durumlarda da yine çoğunlukla konservatif tedavi uygulanır. Diğer karpal kemiklerde olduğu gibi, travma sonrası kırık saptanmayan ağrılı durumlarda konservatif tedaviye rağmen ağrının devam etmesi halinde de MR görüntüleme ile ileri inceleme, gizli hasarları ortaya koyarak tedavinin etkinliğine yardımcı olabilir. ${ }^{[5]}$ Hastaya kırığın kaynamayabileceği anlatılmalıdır. Bu durum şikayete yol açarsa, ağrıya neden olan parça eksize edilebilir.

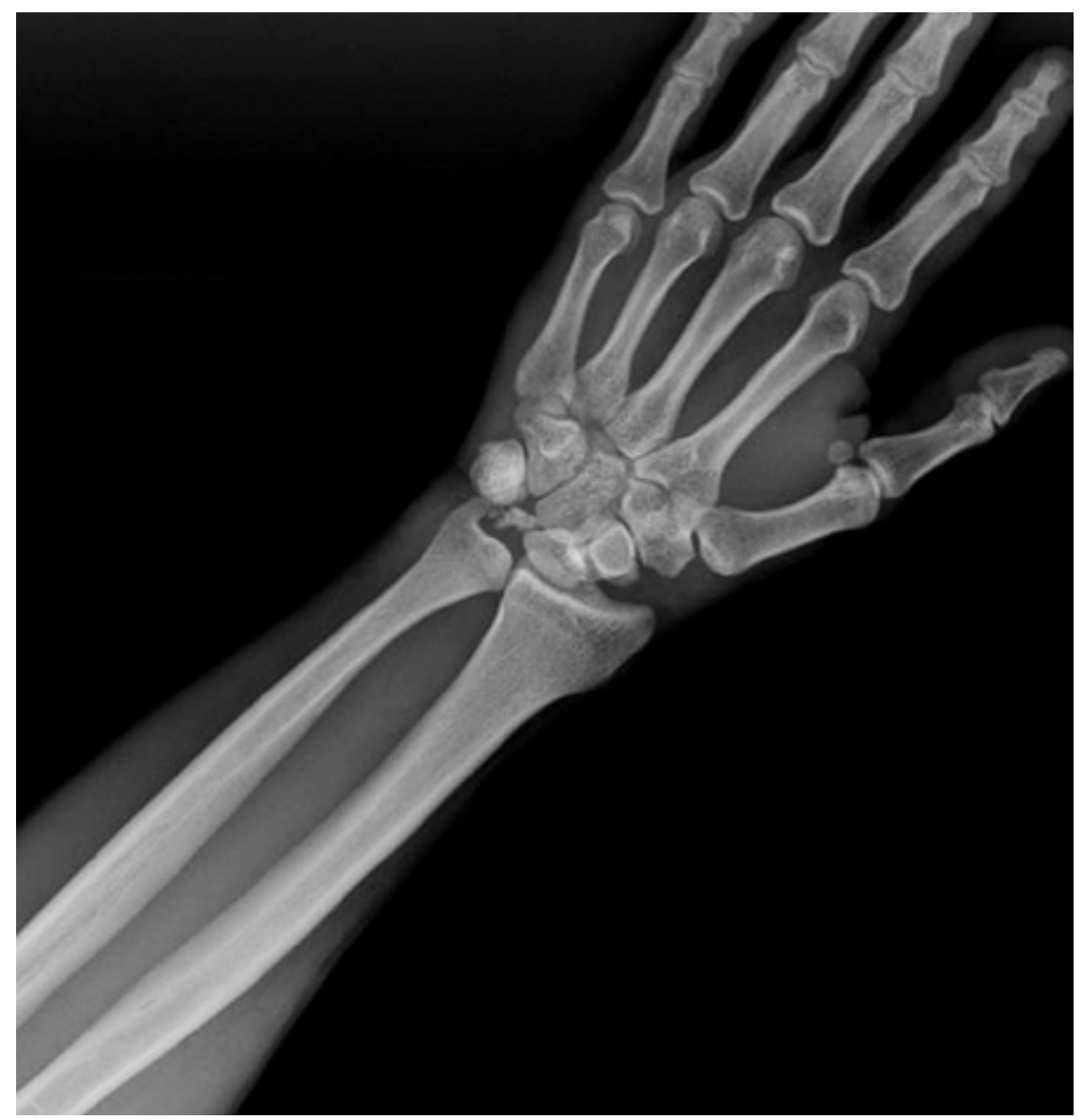

Şekil 2. Perilunat çıkıkla birlikte görülen trikuetrum kırı̆̆ı. 
Trikuetrum cisim kırığının da, her ne kadar daha ağır travmalar sonucunda veya perilunat çıkık varlığında görülse de, tedavisi ilk olarak konservatiftir; kaynamaması nadirdir. Trikuetrum cisim kırı̆ı̆ın geç (travmadan bir ay sonra) tanınıp sekiz haftalık alçı tedavisine rağmen kaynamadığı bir hastada, kemik grefti kullanılarak başarılı osteosentez bildirilmiştir. ${ }^{[10]}$ Trikuetrum cisim ve dorsal kırığının birlikte görüldüğü bir başka olgu ise beş haftalık alçı tedavisi ile tamamen iyileşmiştir. $^{[11]}$ Belirgin biçimde ayrışmış kırıklarda cerrahi tedavi gündeme gelebilir. İnstabilite saptanan durumlarda, erken bağ onarımı ile birlikte kırığın cerrahi tedavisi yapılmalıdır. ${ }^{[1]}$ Radyografilerde instabilite bulgusu olmayan, tek başına görülen cisim kırıklarında dahi muhtemel bağ lezyonları olabileceği akılda tutulmalı hatta MR ile aranmalıdır.

Önceden belirtildiği gibi volar kopma kırıkları oldukça nadirdir. MR görüntüleme ile muhtemel instabilite araştırılmalı ve tedavi, kopan küçük parçanın tespiti yerine karpal stabilitenin yeniden oluşturulmasına odaklanmalıdır.

\section{TRAPEZIUM KIRIKLARI}

Karpal kemikler arasında üçüncü sıklıkta kırılan trapeziumdur. Yine de tüm karpal kemik kırıklarının \%1-5'ini ancak oluşturur. ${ }^{[1]}$ Bu kırıkların çoğu yüksek enerjili yaralanmalar sonucunda ve genellikle el bileğinde ek kırıklarla birlikte görülür. ${ }^{[12]}$ Tek başına görülen trapezium kırıklarının bildirildiği olgu sunumları vardır. [13,14] Walker tarafindan, 1) vertikal transartiküler kırık, 2) horizontal kırık, 3) dorsal radyal çıkıntı kırığı, 4) anterior mediyal kenar kırı̆g ve 5) parçalı kırık olmak üzere, beş farklı kırık tipi tarif edilmiş, ${ }^{[15]}$ daha sonra da trapezium cisminin koronal kırığı bildirilmiştir. ${ }^{[16]}$

Trapezium, anatomik olarak metakarp ve skafoid arasında nispeten korunaklı bir konumda olduğundan direkt darbelere uzaktır. Genellikle, el üstüne düşme ile başparmak metakarpına binen yüklerin trapeziuma iletilmesi sonucunda kırık meydana gelir. Kırılan parçanın ve buna bağlı olan metakarpın proksimale doğru yer değiştirmesi ile eklemde subluksasyon veya çıkık gelişebilir. Birinci karpometakarpal (KMK) eklemin izole çıkığı da nadir bir yaralanmadır. Bikonkav eyer tarzındaki bu eklemin, 16 farklı bağdan oluşan kalın eklem kapsülü sayesinde, stabilitesi yüksektir. ${ }^{[17]}$ Fleksiyondaki metakarpa binen aksiyel yükler sonucunda, trapeziumun dorsaline doğru çıktığı ve bu esnada trapeziumda da kırık oluşabildiği düşünülmektedir. ${ }^{[17]}$ Anatomik yapıların yakın komşuluğundan dolayı farklı klinik tablolar da oluşabilir. EPL (extensor pollicis longus) tendon disfonksiyonu ile başvuran bir hastada, buna neden olarak trapeziumun kaynamamış kırı̆̆ı ve eşlik eden KMK subluksasyonu saptanmıştır. ${ }^{[18]}$ Başka bir çalışmada ise radyal arter yaralanmasının görüldüğü üç trapezium kırı̆̆ı bildirilmiştir. Radyal arter yaralanması, bir hastada trafik kazası sonrası açık kırıklı çıkığa bağlı olarak olay anında, diğer hastada internal tespit esnasında, son hastada ise implant çıkarılması sırasında gelişmiştir. ${ }^{[19]}$

\section{Tedavi}

Birinci sıranın en önemli eklemi olan trapeziometakarpal eklemin uygun redükte edilmemiş kırıkları ciddi morbidite yaratmaktadır. Bu kırıklar her zaman kolaylıkla tanınamadığından, belki de tedavinin ilk basamağını özel çekim pozisyonları ve BT ile aramak oluşturmalıdır. El tam pronasyonda iken çekilen gerçek anteroposterior (AP) grafi trapezium ve metakarp kaidesini gösterir. Kenar kırığından şüpheleniyorsa karpal tünel grafisi istenebilir. Ancak bütün özel grafilere rağmen, tüm karpal kemiklerde olduğu gibi, kırık saptanamayabilir. Bu yüzden, klinik şüphe varsa, erken dönemde BT istenmelidir. ${ }^{[16,20]}$

Alçı ile konservatif tedavi, yer değiştirmemiş ve eklemi bozmamış kırıklarda uygulanabilir. Skafoid kırıklarında olduğu gibi, az bir miktar ayrışma bile kırığın iyileşme imkanını azaltır. ${ }^{[1]}$ Bu yüzden, ayrışmış kırıkların anatomik olarak tedavi edilmesi ortak bir kanıdır. ${ }^{[12,16,21,22]}$ Kapalı redüksiyon ve perkütan pinleme bunun için bir seçenek olsa da, bu yöntemle uyumlu bir eklem yaratmak oldukça zordur. Araştırmacılar genellikle açık redüksiyon ile tespiti önermektedirler. ${ }^{[21-23]}$ Ayrıca internal tespitin artroskopik yardımlı yapıldığı bir olgu da bildirilmiştir. ${ }^{[24]}$ Trapezium kırıklarında karpal tünel sendromu, tendinit veya FCR (flexor carpi radialis) tendon kopması gibi kronik durumlar meydana gelebilir. Semptomatik hale gelen durumlarda kırık parçanın çıkarılması önerilir.

\section{KAPITATUM KIRIKLARI}

Kapitatum, proksimalde skafoid ve lunat ile, distalde 3. metakarp ile eklem yaparak el ve el bileğinin merkezi kolonunu oluşturur. Bu sayede, yaralanmalardan bir ölçüde korunmaktadır. Tek başına olan kırıklarının oranı, tüm el bilek kırıklarının \%0,3'ü olarak bildirilmiştir (Resim 3, 4). ${ }^{[25]}$ Kırıkları tek başına olabilirse de, genellikle transskafoid perilunat çıkıkları ile birlikte görülür. Bu ağır durumlarda, skafoid kırı̆ğ ile beraber kapitatum başııın kırıldığı, proksimal parçanın uzun ekseni etrafında $180^{\circ}$ dönerek lunat ile olan eklem yüzünün artık distalde olduğu bir yaralanma da görülebilmektedir. Fenton tarafindan skafo-kapitat kırık sendromu olarak adlandırılan bu yaralanma şekli, literatürde ilk kez Perves ve arkadaşları tarafından 

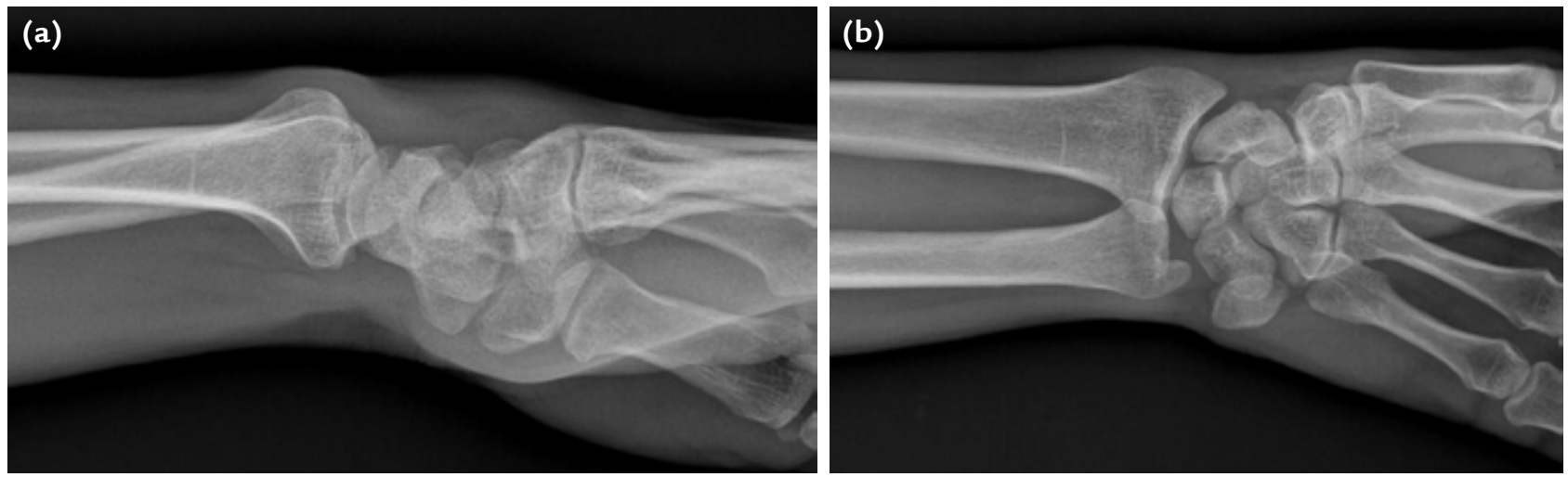

Şekil 3. a, b. El bilek travması sonucu başvuran hastanın AP (a) ve lateral (b) grafilerinde belirgin bir kırık hattı görülmüyor.

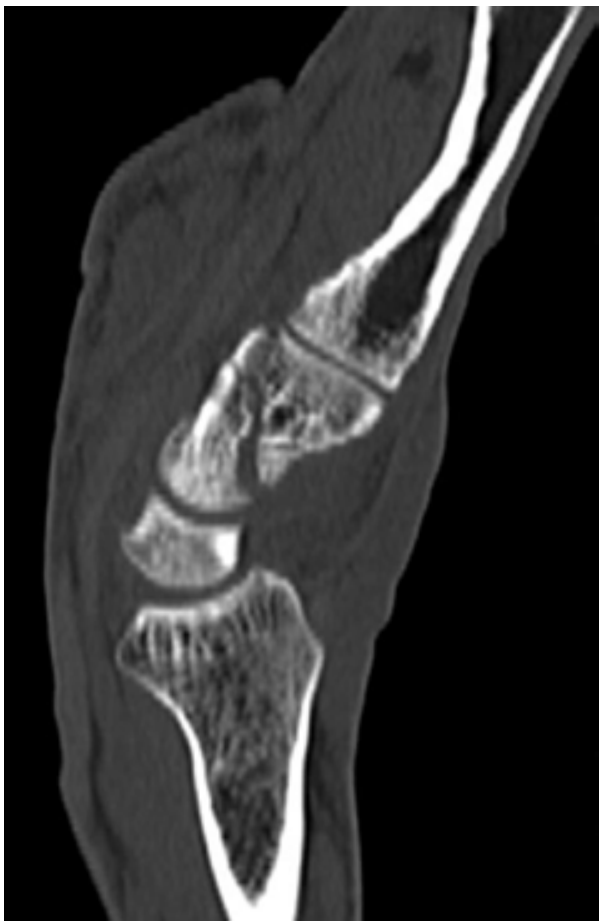

Şekil 4. Aynı hastanın (Şekil 3) BT'sinde ise belirgin ve hafif ayrışmış kapitat kırığı görülüyor.

bildirilmiştir. ${ }^{[26]}$ Bu kırık, yüksek enerjili bir düşme sonucu bileğin aşırı ekstansiyona ve radyal deviyasyona gelmesi sonucunda olur. Skafoidin kırılmasını takiben, radiusun dorsal kenarına dayanan kapitatum kırılır. El bileği nötral durumuna dönerken, karpal bölgedeki kısalma proksimal parçanın redüksiyonunu engeller. Bileğin artan fleksiyonunda ise kapitatumun distal parçası proksimal parçasını döndürerek eklem yüzünün tam tersi yönde yer değiştirmesine neden olur. $\mathrm{Bu}$ durumun tanısı oldukça zor olduğundan, tedavi gecikmiş ve yetersiz olabilir ki zaten Fenton sendromunun tedavisi, eşlik eden yumuşak doku, kıkırdak ve kemik lezyonları nedeniyle oldukça zordur. ${ }^{[26]}$ Tedavinin gecikmesi de posttravmatik artrit, avasküler nekroz ve kaynamamaya neden olabilir.

\section{Tedavi}

Kapitatum başının neredeyse tamamı eklem kıkırdağı ile çevrilidir. Skafoide benzer olarak besleyici damarı distalden girer ve kan akımı geriye doğru olur. Bu akımı bozan kapitatum başı kırıklarında da, tıpkı proksimal skafoid kırıklarında olduğu gibi, kanlanma ve beslenme sorunları gelişerek iyileşme süresi uzar, sonuçlar kötüleşir. Bu kırıklar oluş itibariyle instabildir ve tüm bu nedenlerden ötürü, cerrahi dışı tedavi seçildiğinde sıklıkla geç kaynama veya kaynamama ile sonuçlanır. ${ }^{[27]}$

Ayrışmış kırıklar, ayrışmamış fakat geç tanınmış kırıklar ve trans-skafoid, trans-kapitat perilunat kırıklı çıkıkların tedavisi için açık repozisyon ve internal tespit tercih edilmelidir. Dorsal kesi ile 3. ve 4. ekstansör kompartmanlar arasından ekleme ulaşıldığında, el bileğinin fleksiyonu ile kapitatumun başı rahatça ortaya konulur. Başın $180^{\circ}$ dönmüş olabileceğine dikkat edilmelidir. Perilunat kırıklı çıkıklarda, median sinirin yaralanması veya basitçe basıya uğraması nedeniyle, buna ait bulgular da olabilir. Bu durumlarda, volar kesi ile karpal tünel gevşetilmelidir. Ayrıca bu kesi uzatılarak, median sinir ve fleksör tendonların ekarte edilmesi ile volar kapsüle rahatlıkla ulaşılabilmekte ve dorsal kesiden yerine oturtulamayan lunat çıkı̆̆ına müdahale edilebilir. Ancak, literatürde bu tip yaralanmalarda volar mi, dorsal mi yoksa her iki yaklaşımın da mı kullanılması gerektiğine dair görüş birliği yoktur. ${ }^{[28]}$ Ayrıca kırıklarla birlikte olan perilunat çıkıkların bağ yırtıkları ile birlikte olan çıkıklara göre daha kolay iyileştiği ve sonuçlarının daha iyi olduğu gözlemlenmiştir. ${ }^{[28]}$ Bunun nedeni olarak, bağ yırtıklarının sağlam tamirinin ve sonrasında korunmasının zor, buna bağlı olarak da iyileşmenin zayıf olması düşünülmüştür. 


\section{HAMATUM KIRIKLARI}

Diğer karpal kemik kırıkları gibi nadir görülür. Hamatum çengeli ise özel yapısı nedeni ile risk altındadır. Hamatum kaidesinden hipotenar bölgeye uzanan bu çıkıntı, flexor digiti minimi, opponens digiti minimi, hipotenar kaslar, pisohamat bağlar ve transvers karpal bağ distal kısmının yapışma yeri olması açısından önemlidir. ${ }^{[1]}$ Ayrıca 4. ve 5. parmakların fleksör tendonlarına pulley görevi görür.

Kırık iki mekanizma ile oluşur:

1. El ayası üzerine düşme sonucu meydana gelen direkt travma.

2. Tenis ve golf benzeri raket ve sopa sporlarında meydana gelen tekrarlayıcı mikrotravmalar.

Hamatum çengelinin üstü basmakla hassastır. Bu bölge pisiform kemiğin yaklaşık $2 \mathrm{~cm}$ distalinde ve radyal tarafında bulunmaktadır. Ağrı, aktif kavrama ile artar; 4. ve 5. parmağın dirence karşı fleksiyonundaki ağrının ulnar deviyasyon ile artması, radyal deviyasyon ile azalması ise fleksör tendonları tahriş eden hamatum çengeli kırığına işaret eder. Gecikmiş kırıklar ise, ulnar sinir parestezisi, kavrama gücünde azalma, 4. ve/ veya 5 . parmağın yüzeyel ve/veya derin fleksör tendon kopması ile kendini gösterir.

Hamatum çengeli kırı̆ı̆ın kaynamama riski yüksektir. Bunun nedenleri arasında kırık parçanın hareketliliği, hamatumun kan akımının zayıflığı ve kırı̆ıın geç teşhisi sayılabilir. ${ }^{[29]}$ Kırığın teşhisi için posteroranterior
(PA) grafide çengelin yokluğu, kortikal yüzük bulgusu veya skleroz görülmesi ipucu olabilir. Hamatum çengeli el bileği hafif supinasyon ve tam radyal deviyasyondayken çekilen grafilerde ve karpal tünel grafisinde görülebilir (Şekil 5). Her ne kadar özel grafi pozisyonları tarif edilmiş olsa da, günümüzde BT'nin radyografilere üstünlüğü gösterilmiştir. ${ }^{[30]}$ Ancak bu özel grafileri ve BT'yi istemek için, öncelikle bu durumdan şüphelenmek ve kırığı aramak gerektiği açıktır. Bu amaçla, hem akut hem de geç dönemde uygulanabilecek, kolay, ucuz, duyarlı ve özgün bir test olan hamatum çengeli çekme testi bildirilmiştir. ${ }^{[31]}$

\section{Tedavi}

Akut ve ayrışmamış kırıklar alçılama ile iyileşebilir. Daha sık görülen kronik kırıklar veya ayrışmış kırıklar için ise, genellikle önerilen tedavi çengelin kırık parçasının çıkartılmasıdır. ${ }^{[1]}$ Bildirilen sonuçlar genellikle tatminkardır. Ancak, parçanın çıkarılmasının küçük parmağın fonksiyonunu etkileyeceğini ve bundan dolayı açık redüksiyon - internal tespit yapılmasını öneren yazarlar da vardır. ${ }^{[29,32]}$ Yine de, parçanın çıkarılması ile tedavi edilen yüksek seviye amatör sporcular bile kırık öncesi performanslarına dönebilmektedir. ${ }^{[33]}$ Cerrahi esnasında, yakın komşuluğundan dolayı ulnar sinirin ve özellikle motor dalının görülmesi ve korunmasına dikkat edilmelidir.

Hamatum cisim kırıkları çengel kırıklarından daha nadirdir. Genellikle direkt travma veya yüksek enerjili

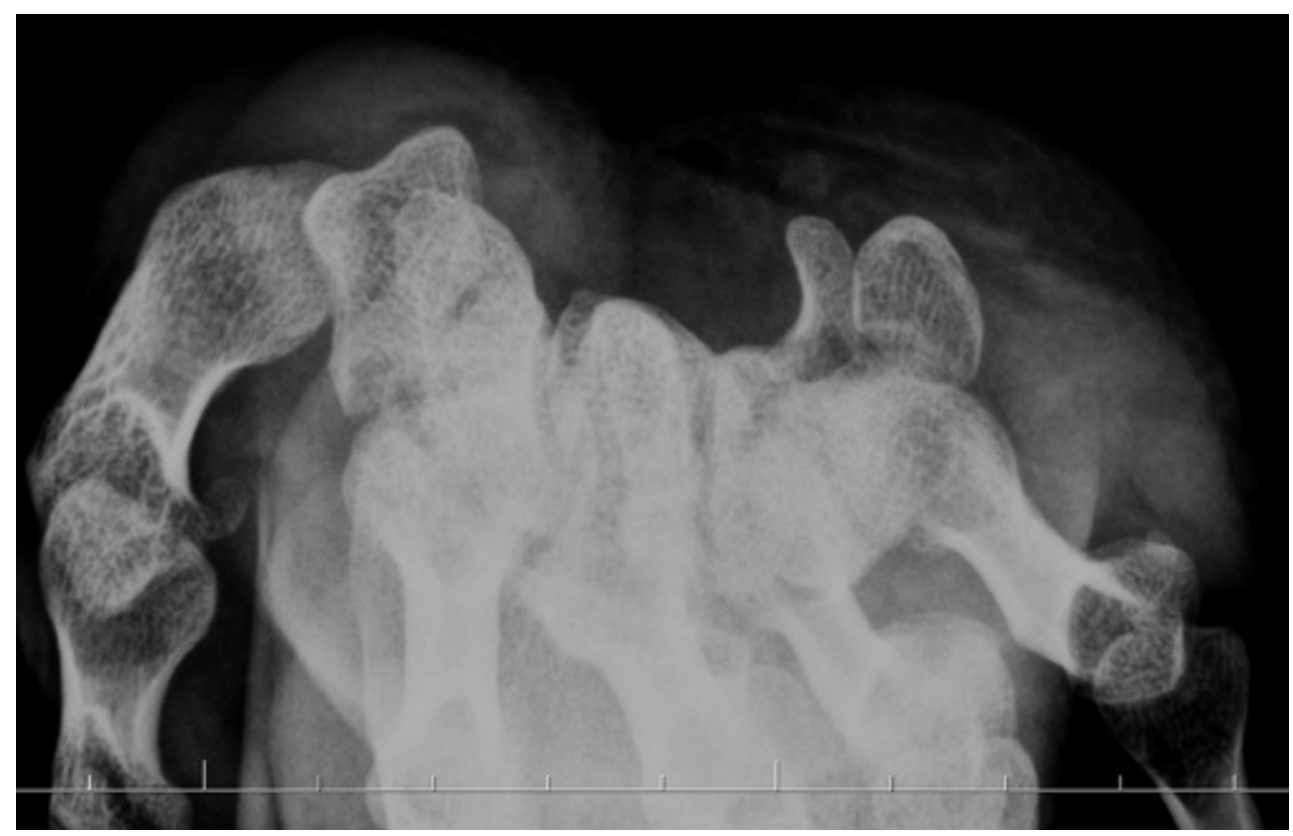

Şekil 5. Karpal tünel grafisinde hamatumun çengelinin görünümü. 
yaralanma sonucu meydana gelir. Bu kırıklara 4. ve 5. metakarpların, hamatumun çıkıkları, karpal instabilite, ulnar sinir felci ve kompartman sendromu eşlik edebilir. Konservatif tedavi, ancak çok az ayrışmış veya hiç ayrışmamış kırıklar için seçilmelidir; 4. ve 5. metakarpların hamatumla yaptıkları eklem yaklaşık $30^{\circ}$ 'ye kadar harekete izin verip elin kavraması için önemli olduğundan, ayrışmış kırıklar açık redüksiyon ve internal tespit ile cerrahi olarak tedavi edilmelidir. ${ }^{[1]}$

\section{PISIFORM KIRIKLARI}

Pisiform, fleksör karpi ulnaris tendonu içinde yer alan bir sesamoid kemiktir. Genellikle, elin ulnar tarafı üstüne düşmek gibi direkt travma sonucu meydana gelir. Rutin el bilek grafileri ile kolaylıkla gözden kaçabileceğinden, şüphe olması durumunda BT ile incelenmelidir (Şekil 6). ${ }^{[23]}$

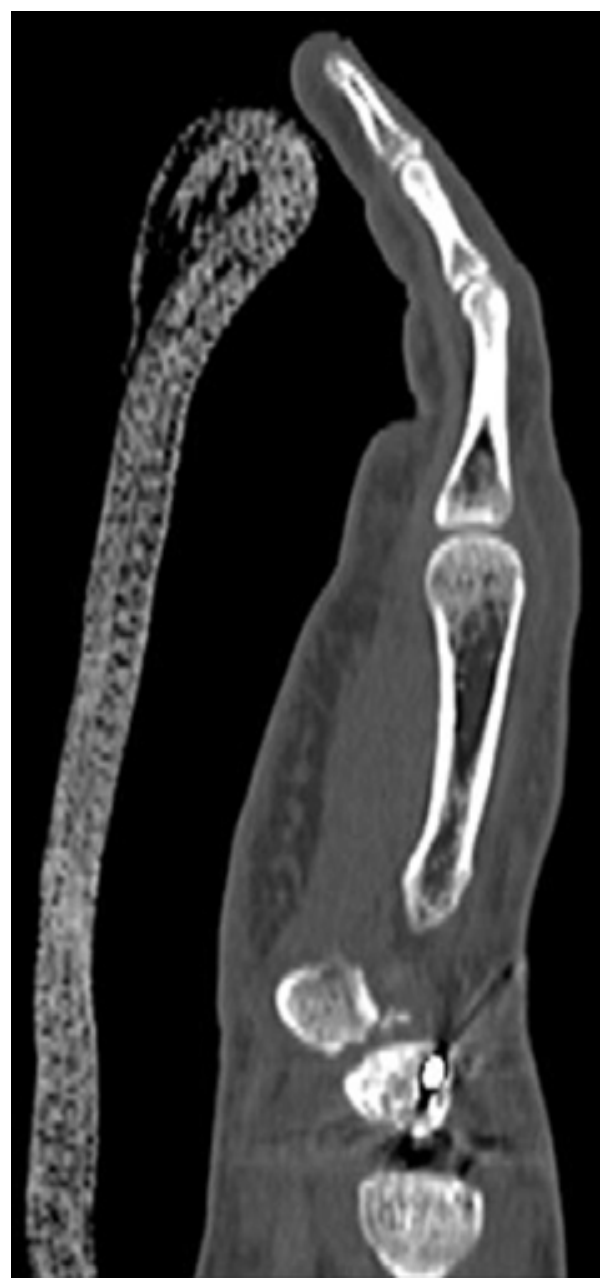

Şekil 6. Perilunat çıkık nedeniyle tedavi edilen hastada trikuetro-pisiform eklemdeki yaralanma ve pisiformun minik parçalı kırıkları görülmekte.

\section{Tedavi}

Pisiform kırıkları, ağırlıklı olarak konservatif yöntemlerle tedavi edilir. Özellikle ayrışmamış akut kırıklara 3-6 haftalık alçı uygulanır. Ayrışmış kırıklarda vida ile osteosentez mümkündür. [23] Parçalı kırıklar ve semptom veren kaynamamalar ise pisiformun çıkarılması ile tedavi edilir. Hamatum çengelinin çıkarılmasında olduğu gibi, yakın komşuluğundaki ulnar damar sinir paketine dikkat edilmelidir.

\section{TRAPEZOID KIRIKLARI}

Karpal kemikler arasında en az kırılan trapezoiddir. ${ }^{[1]}$ Karpal kemiklerin anatomik dizilimi ve trapezium, skafoid ve kapitatuma sıkı bağlarla bağlanması onu kırık ve çıkıklardan korur. ${ }^{[34]}$ Yaralanması, genellikle 2. metakarp üzerinden aksiyel olarak iletilen kuwetler sonucu, indirekt mekanizma ile olur. ${ }^{[2]}$ Diğer nadir görülen karpal kırıklar gibi, şüphe oluştuğunda BT ile aranmalıdır.

\section{Tedavi}

Ayrışmamış kırıklar konservatif olarak tedavi edilebilir. Ayrışmış kırıklarda ve karpometakarpal kırıklı çıkıklarda cerrahi olarak tespit gereklidir. ${ }^{[23]}$ Çıkarılması, 2. metakarpın proksimale doğru kayma potansiyelinden dolayı, kontrendikedir. Devam eden şekil bozukluğu, instabilite ve artroz gibi kronik sekellerde, karpometakarpal artrodez uygulanmalıdır.

\section{LUNAT KIRIKLARI}

Lunat kemik kendisine ait, radiusun distalindeki oluğunda, izole travmalardan oldukça korunaklıdır. Dolayısıyla, tek başına kırıklarına çok nadir rastlanır. Ancak, lunat kırıkları tartışmalıdır; bazı yazarlar Kienböck hastalığını da kırık grubuna dahil etmekte ve lunatın kırık oranlarını yükseltmektedirler. Bu yazıda Kienböck hastalığından bahsedilmeyecektir.

Akut kırıkları ise tüm karpal kırıkların \%1'ini meydana getirmektedir. Genellikle, genç bireylerde yüksek enerjili yaralanmalar sonucunda, diğer karpal yaralanmalarla birlikte oluşur. ${ }^{[35]}$ Dorsifleksiyon ve ulnar deviyasyondaki el bileğine binen aksiyel yüklenme ile, kapitatın proksimale doğru yer değiştirip lunatı zorlaması ile gelişir. Tanısında BT çok yardımcıdır (Şekil 7). Proksimal eklem yüzünün lunat gövdesinden ayrıldığı kırıklar genellikle Kienböck hastalığının sonucudur. ${ }^{[1]}$

\section{Tedavi}

Akut veya kronik olsun, lunat kırıklarının tedavisi üzerinde fikir birliğine varılamamıştır. ${ }^{[35]}$ Ayrışmamış 


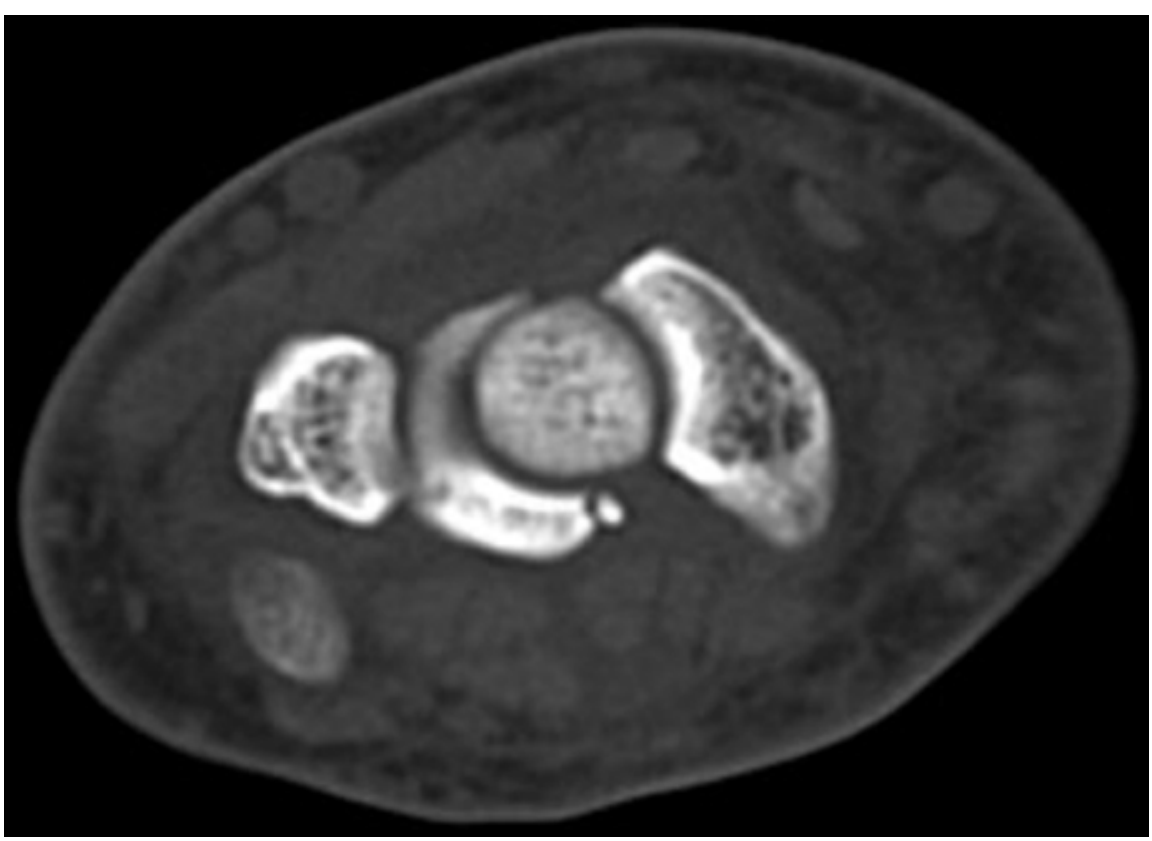

Şekil 7. Lunat volar köşesinin izole kopma kırı̆̆ı görülmekte.

kırıklar ve küçük kopma kırıkları için en az altı haftalık alçılama önerilir. Ayrışmış büyük parçaların varlığında ise, açık redüksiyon - internal tespit yapılarak anatominin düzeltilmesi, olası avasküler nekroz ve artrozun önlenmesi hedeflenmelidir. Kronik karpal instabilite ve artroz ile başvuran geç olgularda ise, proksimal sıranın çıkarılması ve el bilek artrodezi gibi kurtarma ameliyatları gündeme gelir.

\section{KAYNAKLAR}

1. Geissler WB, Slade JF. Fractures of the carpal bones. In: Wolfe SW, Hotchkiss RN, Pederson WC, Kozin SH, editors. Green's Operative Hand Surgery. 6th ed. Philadelphia: Churchill Livingstone Elsevier; 2011. p.639-707.

2. Garcia-Elias M, Dobyns JH, Cooney WP 3rd, Linscheid RL. Traumatic axial dislocations of the carpus. J Hand Surg Am 1989;14(3):446-57.

3. Komura S, Yokoi T, Nonomura H, Tanahashi H, Satake T, Watanabe N. Incidence and characteristics of carpal fractures occurring concurrently with distal radius fractures. J Hand Surg Am 2012;37(3):469-76. CrossRef

4. Al Rashid M, Rasoli S, Khan WS. Non-union of isolated displaced triquetral body fracture -- a case report. Ortop Traumatol Rehabil 2012;14(1):71-4.

5. Bergh TH, Lindau T, Bernardshaw SV, Behzadi M, Soldal LA, Steen K, Brudvik C. A new definition of wrist sprain necessary after findings in a prospective MRI study. Injury 2012;43(10):1732-42. CrossRef

6. Gaebler C, McQuenn MM. Carpus fractures and dislocations. In: Bucholz RW, Court-Brown CM, Heckman JD, Tornetta $\mathrm{P}$, editors. Rockwood and Green's Fractures in Adults. 7th ed. Philadelphia, Pa: Lippincott Williams \& Wilkins; 2010. p.781-828.
7. Levy M, Fischel RE, Stern GM, Goldberg I. Chip fractures of the os triquetrum: the mechanism of injury. J Bone Joint Surg $\mathrm{Br} 1979 ; 61-\mathrm{B}(3): 355-7$.

8. Garcia-Elias M. Dorsal fractures of the triquetrum-avulsion or compression fractures? J Hand Surg Am 1987;12(2):266-8.

9. Smith DK, Murray PM. Avulsion fractures of the volar aspect of triquetral bone of the wrist: a subtle sign of carpal ligament injury. AJR Am J Roentgenol 1996;166(3):609-14.

10. Sin $\mathrm{CH}$, Leung YF, Ip SP, Wai YL, Ip WY. Non-union of the triquetrum with pseudoarthrosis: a case report. J Orthop Surg (Hong Kong) 2012;20(1):105-7.

11. Yildirim C, Akmaz I, Keklikçi K, Kiral A. An unusual combined fracture pattern of the triquetrum. J Hand Surg Eur Vol 2008;33(3):385-6. CrossRef

12. McGuigan FX, Culp RW. Surgical treatment of intraarticular fractures of the trapezium. J Hand Surg Am 2002;27(4):697-703.

13. Inston N, Pimpalnerkar AL, Arafa MA. Isolated fracture of the trapezium: an easily missed injury. Injury 1997;28(7):485-8.

14. Strobl FF, Notohamiprodjo M, Schmidt GP. Isolated fracture of the trapezium, a rare wrist fracture after a fall on the hand. Rofo 2012;184(7):655-7. CrossRef

15. Walker JL, Greene TL, Lunseth PA. Fractures of the body of the trapezium. J Orthop Trauma 1988;2(1):22-8.

16. Binhammer $P$, Born $T$. Coronal fracture of the body of the trapezium: a case report. J Hand Surg Am 1998;23(1):156-7.

17. Parker WL, Czerwinski M, Lee C. First carpal-metacarpal joint dislocation and trapezial fracture treated with external fixation in an adolescent. Ann Plast Surg 2008;61(5):506-10. CrossRef

18. Pai V, Warbrick-Smith J, Pai V. Extensor pollicis longus dysfunction associated with non-united fracture of the trapezium. J Hand Microsurg 2010;2(1):42-4. CrossRef 
19. Checroun AJ, Mekhail AO, Ebraheim NA. Radial artery injury in association with fractures of the trapezium. J Hand Surg Br 1997;22(3):419-22.

20. Welling RD, Jacobson JA, Jamadar DA, Chong S, Caoili EM, Jebson PJ. MDCT and radiography of wrist fractures: radiographic sensitivity and fracture patterns. AJR Am J Roentgenol 2008;190(1):10-6.

21. Garneti N, Tuson CE. Sagittally split fracture of trapezium associated with subluxated carpo-metacarpal joint of thumb. Injury 2004;35(11):1172-5.

22. Horch R. A new method for treating isolated fractures of the os trapezium. Arch Orthop Trauma Surg 1998;117(3):180-2.

23. Schädel-Höpfner $M$, Prommersberger $K J$, Eisenschenk $A$, Windolf J. Treatment of carpal fractures. Recommendations of the Hand Surgery Group of the German Trauma Society. Unfallchirurg 2010;113(9):741-54. CrossRef

24. Wiesler ER, Chloros GD, Kuzma GR. Arthroscopy in the treatment of fracture of the trapezium. Arthroscopy 2007;23(11):1248. e1-4.

25. Colonna MR, Crisafulli C, Stagno d'Alcontres F, Risitano G. Isolated fracture of the capitate with rotation of the proximal fragment. Case report. Chir Main 2013;32(3):189-91. CrossRef

26. Marcuzzi A, Ozben H, Russomando A, Petit A. Chronic transscaphoid, transcapitate perilunate fracture dislocation of the wrist: Fenton's syndrome. Chir Main 2013;32(2):1003. CrossRef

27. Cooney AD, Stuart PR. Symptomatic nonunion of an isolated capitate fracture in an adolescent. J Hand Surg Eur Vol 2013;38(5):565-7. CrossRef
28. Apostolides JG, Lifchez SD, Christy MR. Complex and rare fracture patterns in perilunate dislocations. Hand (N. Y.) 2011;6(3):287-94. CrossRef

29. Taleb C, Murachowsky J, Ruggiero GM. Hamate hook nonunion treated with a hook plate: case report and surgical technique. Tech Hand Up Extrem Surg 2012;16(4):194-7. CrossRef

30. Andresen R, Radmer S, Sparmann M, Bogusch G, Banzer D. Imaging of hamate bone fractures in conventional $X$-rays and high-resolution computed tomography. An in vitro study. Invest Radiol 1999;34(1):46-50.

31. Wright TW, Moser MW, Sahajpal DT. Hook of hamate pull test. J Hand Surg Am 2010;35(11):1887-9. CrossRef

32. Watson HK, Rogers WD. Nonunion of the hook of the hamate: an argument for bone grafting the nonunion.J Hand Surg Am 1989;14(3):486-90.

33. Devers BN, Douglas KC, Naik RD, Lee DH, Watson JT, Weikert DR. Outcomes of hook of hamate fracture excision in highlevel amateur athletes. J Hand Surg Am 2013;38(1):72-6. CrossRef

34. Miyawaki T, Kobayashi M, Matsuura S, Yanagawa H, Imai T, Kurihara K. Trapezoid bone fracture. Ann Plast Surg 2000;44(4):444-6.

35. Hsu AR, Hsu PA. Unusual case of isolated lunate fracture without ligamentous injury. Orthopedics 2011;34(11):e7859. CrossRef 